\title{
Prothrombotic Gene Variants and Mortality after Cerebral Ischemia of Arterial Origin
}

\author{
D. Martijn O. Pruissen ${ }^{a}$ Frits R. Rosendaal ${ }^{c, d}$ Catharina J.M. Frijns ${ }^{a}$ \\ L. Jaap Kappelle ${ }^{a}$ Hans L. Vos ${ }^{d}$ Ale Algra ${ }^{a-c}$ on behalf of the SMART Study Group

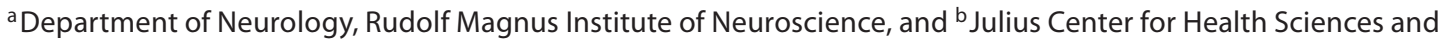 \\ Primary Care, University Medical Center Utrecht, Utrecht, and ${ }^{\mathrm{C} D e p a r t m e n t}$ of Thrombosis and Hemostasis and \\ ${ }^{\mathrm{d}}$ Einthoven Laboratory for Experimental Vascular Medicine, Leiden University Medical Center, Leiden, The Netherlands
}

\section{Key Words}

Genetics $\cdot$ Cerebral ischemia $\cdot$ Mortality

\begin{abstract}
Background: Several functional prothrombotic gene variants have been associated with cerebral ischemia and myocardial infarction. We hypothesized that such gene variants may also be associated with mortality after cerebral ischemia of arterial origin because of an increased risk of fatal vascular events. Methods: We performed a case-control study in 316 long-term survivors and 887 patients with recent cerebral ischemia of arterial origin. False discovery rate $q$ values were calculated to account for multiple testing. The mean duration between occurrence of cerebral ischemia and DNA collection was 16.8 years in long-term survivors and 3.2 months in recent patients. Results: Two of 23 variants were associated with mortality: the $95 \mathrm{Arg}$ allele of the coagulation factor XIII subunit B (F13B) His95Arg variant (OR, 1.5 for Arg/Arg and His/Arg vs. His/His genotype; $95 \% \mathrm{Cl}, 1.1-$ $2.2, \mathrm{q}=0.29$ ) and the $4 \mathrm{G}$ allele of the plasminogen activator inhibitor-1 (PAI-1) $4 \mathrm{G} / 5 \mathrm{G}$ variant (OR, 1.5 for $4 \mathrm{G} / 4 \mathrm{G}$ and $5 \mathrm{G} / 4 \mathrm{G}$ vs. $5 \mathrm{G} / 5 \mathrm{G}$ genotype; $95 \% \mathrm{Cl}, 1.1-2.0, \mathrm{q}=0.29)$. Both associa-
\end{abstract}

tions disappeared after accounting for multiple testing. Data analysis restricted to recently deceased patients $(n=133)$ yielded similar results. Conclusions: In this hospital-based study none of 23 prothrombotic gene variants were associated with long-term mortality after cerebral ischemia of arterial origin. Prothrombotic gene variants do not appear to play an important role in long-term mortality after cerebral ischemia.

Copyright $\odot 2011$ S. Karger AG, Basel

\section{Introduction}

Twin and epidemiological studies suggest a genetic basis for cerebral ischemia [1]. Genetic factors seem more important in cerebral ischemia of arterial origin than in other stroke subtypes [2]. Several gene variants involved in hemostasis have been associated with cerebral ischemia and myocardial infarction [3, 4]. Most of these variants were also reported to be functional (i.e. to have an effect on protein level or function). Most genetic association studies so far have focused on first cerebral or myocardial ischemia. We hypothesized that pro-

\section{KARGER}

Fax +41613061234 E-Mail karger@karger.ch www.karger.com
(C) 2011 S. Karger AG, Basel

0251-5350/11/0372-0109\$38.00/0

Accessible online at:

www.karger.com/ned
Ale Algra

Julius Center for Health Sciences and Primary Care, University Medical Center Utrecht STR 6.131, PO Box 85500

NL-3508 GA Utrecht (The Netherlands)

Tel. +31 88755 9350, E-Mail A.Algra@ umcutrecht.nl 
thrombotic gene variants may be associated with mortality after cerebral ischemia of arterial origin because of an increased risk of fatal vascular events. If specific gene variants increase the risk of mortality after cerebral ischemia of arterial origin (CIAO), this would aid in the determination of prognosis after CIAO and may ultimately even lead to adapted antithrombotic treatment based on a genotype.

\section{Methods}

\section{Study Design}

We performed a novel type of case-control study comparing genotype frequencies between recent patients (cases) and longterm survivors (controls) after CIAO. The study principle is that a variant associated with mortality is more common in recent patients than in long-term survivors. Details of the study design were published previously [5]. The study was approved by the medical ethics committee of the University Medical Center Utrecht, the Netherlands. All patients gave written informed consent.

\section{Patients}

All participants were patients with nondisabling CIAO who were referred to the University Medical Center Utrecht and were included in the SMART (Second Manifestations of Arterial disease) study [6], ESPRIT (European/Australasian Stroke Prevention in Reversible Ischemia Trial) [7], the Utrecht Stroke Database (USDB) or the LiLAC (Life Long After Cerebral ischemia) study [8]. Cases were patients with recent CIAO from SMART, ESPRIT and USDB. All patients included in SMART, ESPRIT and USDB were sampled from the same general Dutch population. SMART is an ongoing prospective single-center cohort study in patients aged 18-80 years with manifest arterial disease or cardiovascular risk factors who were referred since 1996 to the University Medical Center Utrecht. All SMART participants underwent a vascular screening programme including DNA collection. ESPRIT was a randomized controlled trial in which treatment with aspirin plus dipyridamole or oral anticoagulants was compared with aspirin alone in patients with CIAO. The USDB is a prospective registry for stroke patients referred to the department of neurology of the University Medical Center Utrecht. Controls were longterm survivors after CIAO from the LiLAC study who suffered from CIAO between 1986 and 1989. Long-term survivors were defined as participants of the LiLAC study who were still alive and gave informed consent for DNA collection between 2002 and 2004. We approached all 198 LiLAC patients who were randomly selected for a home visit between 2002 and 2004 (to assess their quality of life) and we also approached the LiLAC patients who still visited the outpatient clinic of the University Medical Center Utrecht for ongoing care between 2002 and 2004.

We included patients with ischemic stroke, transient ischemic attack (TIA), transient monocular blindness or retinal ischemia, caused by atherosclerosis. Patients with a source of embolism in the heart or another identified cause of stroke were excluded. Cardiac sources were excluded on basis of evaluation of standard electrocardiography (presence of atrial fibrillation), history of recent myocardial infarction and congestive heart failure. Further diagnostic work-up was performed only if the attending neurologist suspected a cardiac source of embolism.

\section{Gene Variant Selection and Genotyping}

We selected gene variants involved in hemostasis based on functionality studies and previous association with ischemic stroke or myocardial infarction. To achieve better coverage of variation within a candidate gene, we also included other variants within selected genes that were studied previously for association with cerebral ischemia or myocardial infarction (without finding an association). Two gene variants (TPA Ins/Del and VWF $\mathrm{G}(-1185) \mathrm{A}$ ) were excluded because of assay failure (see below). We selected 23 variants in 14 genes. Supplementary table 1 (www. karger.com/doi/10.1159/000330353) contains additional information on functionality studies and previous associations with ischemic stroke or myocardial infarction for all selected variants.

DNA was isolated from blood samples or buccal swabs and amplified with polymerase chain reaction. Genotyping of all gene variants but TPA Ins/Del and VWF G(-1185)A was performed with the $5^{\prime}$ nuclease/TaqMan assay [9]. Polymerase chain reactions with fluorescent allele-specific oligonucleotide probes (Assay-by-Design/Assay-on-Demand; Applied Biosystems, Foster City, Calif., USA) were performed on a PTC-225 thermal cycler (Biozym, Hessisch Oldendorf, Germany), and fluorescence end point reading for allelic discrimination was performed on an ABI 7900 HT (Applied Biosystems). Primer sequences, probe sequences, and restriction enzymes used are available on request. Genotyping of TPA Ins/Del and VWF G(-1,185)A was performed with high resolution melting curve analysis [10]. Both variants were excluded from analysis due to assay failure (genotype call rates less than 95\%). All genotypes were determined without knowledge about case-control status or other patient characteristics.

\section{Statistical Analysis}

The relative risk of mortality after CIAO was assessed as an odds ratio (OR) and corresponding 95\% CI with unconditional logistic regression for each gene variant. An odds ratio $>1$ reflects increased mortality. A dominant model of inheritance was used: variant allele heterozygotes and homozygotes were compared with wild-type homozygotes. With a variant genotype frequency of $10 \%$ in controls, we could detect odds ratios of 1.51 and 0.63 with sufficient precision $(\alpha=0.05)$. Hardy-Weinberg equilibrium (HWE) in the control group for each variant was not calculated. Since all control subjects in this study had cerebral ischemia a HWE deviation due to an association between the genetic variant and cerebral ischemia cannot be excluded. Genotype-based analysis does not rely on the assumption of HWE.

To account for multiple testing, false discovery rate $\mathrm{q}$ values were calculated [11]. To calculate the q value, the $p$ values are modified by multiplying them by the number of tests performed and then dividing them by the rank order of each $p$ value (where rank order 1 is assigned to the smallest $p$ value). For each test, the $q$ value is defined as the smallest modified $p$ value among tests with equal or larger rank. The q value estimates the proportion of results declared interesting that are actually false. No conventional $q$ value threshold has been established to separate false discoveries from true discoveries in candidate gene investigations. We used a q value threshold of 0.20 and so should expect up to only $20 \%$ of declared discoveries to be false [12]. 


\section{Results}

A total of 887 patients with recent CIAO (cases) and 316 long-term survivors (controls) were included. We recruited 689 cases from the SMART study, 74 from ESPRIT and 124 from the USDB. Baseline characteristics are provided in table 1. DNA was collected on average 0.27 years (3.2 months) after the qualifying event in cases (qualifying years 1992-2005) and after 16.8 years in controls (qualifying years 1986-1989). Controls were younger at the moment of qualifying event, they were more often women and had less vascular risk factors (except smoking).

The overall call rate for all 23 gene variants was $98.4 \%$ (range 95.3-99.3\%). The mean frequency of genotypes containing at least one variant allele $(100 \%$ minus frequency for frequencies $>50 \%$ ) was $28.1 \%$ in controls. Given this frequency, we could detect odds ratios of 1.33 and 0.74 with sufficient precision $(\alpha=0.05)$. Table 2 shows genotype frequencies in cases and controls and odds ratios for mortality after CIAO. Two variants were associated with mortality: the His95Arg variant of the coagulation factor XIII subunit B (F13B) gene (OR 1.5; 95\% CI 1.1-2.2) and the $4 \mathrm{G} / 5 \mathrm{G}$ variant of the plasminogen activator inhibitor-1 (PAI-1) gene (OR 1.5; 95\% CI 1.1-2.0). Both associations conferred a $\mathrm{q}$ value higher than $0.20(\mathrm{q}=0.29)$.

Follow-up data were available in the cases for 5 years after the qualifying event. During this period 133 cases died (mean duration from qualifying event to death: 3.9 years). Data analysis restricted to these 133 deceased cases yielded genotype frequencies and odds ratios similar to those in table 2 for F13B His95Arg (OR 1.6; 95\% CI 0.93-2.7) and PAI-1 4G/5G (OR 1.6; 95\% CI 0.96-2.7). The results of this subgroup analysis for the other 21 variants were also similar to the overall analysis in table 2 . Exclusion of retinal qualifying events (24 cases and 123 controls) did not essentially change the genotype frequencies and odds ratios from table 2 . Analyses assuming an additive or recessive mode of inheritance revealed no additional associations in both the main analysis and the analysis restricted to deceased cases.

\section{Discussion}

None of 23 prothrombotic gene variants were associated with mortality after CIAO after accounting for multiple testing in this case-control study of 1,203 patients.

To our knowledge, there are no previous studies on the association between gene variation and mortality after CIAO aside from our own previous follow-up study in
Table 1. Baseline characteristics of recent patients (cases) and long-term survivors (controls) after CIAO

\begin{tabular}{|c|c|c|}
\hline & $\begin{array}{l}\text { Cases } \\
(\mathrm{n}=887)\end{array}$ & $\begin{array}{l}\text { Controls } \\
(\mathrm{n}=316)\end{array}$ \\
\hline Mean age & $62(55-70)$ & $56(49-62)$ \\
\hline Male sex & $633(71 \%)$ & $208(66 \%)$ \\
\hline \multicolumn{3}{|l|}{ Qualifying event } \\
\hline Ischemic stroke & $449(51 \%)$ & $175(55 \%)$ \\
\hline TIA & $315(36 \%)$ & $117(37 \%)$ \\
\hline Retinal infarction & $18(2 \%)$ & $1(0 \%)$ \\
\hline Transient monocular blindness & $105(12 \%)$ & $23(7 \%)$ \\
\hline \multicolumn{3}{|l|}{ History } \\
\hline Cerebral ischemia & $190(21 \%)$ & not available \\
\hline Angina pectoris & $60(7 \%)$ & $20(6 \%)$ \\
\hline Myocardial infarction & $106(12 \%)$ & $20(6 \%)$ \\
\hline Diabetes mellitus & $134(15 \%)$ & $11(4 \%)$ \\
\hline Hypertension & $435(49 \%)$ & $101(32 \%)$ \\
\hline Hyperlipidemia & $330(37 \%)$ & $13(4 \%)$ \\
\hline Current smoking & $189(22 \%)$ & $152(48 \%)$ \\
\hline
\end{tabular}

Mean age at qualifying event in years (25th to 75 th percentile range).

which we found no association between gene variation and mortality after CIAO during 4.6 years of mean follow-up [13].

Our study design has strengths and limitations. A substantial proportion of patients with recent CIAO (cases) will become long-term survivors (controls) in the future. This may dilute our results. Therefore, we also performed a subgroup analysis restricted to deceased cases. The results of this analysis are consistent with the overall analysis, confirming the validity of the novel study design we used.

Vascular risk factors were less common in long-term survivors than in recent patients, which was expected because stroke patients with cardiovascular risk factors are likely to be at increased risk of subsequent fatal vascular events. The baseline difference in history of hyperlipidemia is probably explained by the widening of diagnostic criteria for hyperlipidemia over time. We did not adjust for vascular risk factors because environmental factors are unlikely to affect genotype frequencies and to confound genetic associations [14].

DNA collection in cases was performed on average 3.2 months after the qualifying event. We therefore cannot comment on the association between prothrombotic gene variants and short-term mortality. The interpretation of our findings should be restricted to the hospitalbased setting. 
Table 2. Genotype frequency in cases and controls and odds ratios for mortality after CIAO

\begin{tabular}{|c|c|c|c|c|c|c|c|c|c|c|c|}
\hline \multirow{2}{*}{$\begin{array}{l}\text { Gene } \\
\text { symbol }\end{array}$} & \multirow[t]{2}{*}{ Variant } & \multirow{2}{*}{$\begin{array}{l}\text { Ref SNP } \\
\text { ID number }\end{array}$} & \multicolumn{3}{|c|}{ Frequency in cases $(\% ; \mathrm{n}=887)$} & \multicolumn{3}{|c|}{ Frequency in controls $(\% ; \mathrm{n}=316)$} & \multirow{2}{*}{$\begin{array}{l}\text { Odds ratio } \\
(95 \% \mathrm{CI})\end{array}$} & \multirow{2}{*}{$\begin{array}{l}\mathrm{p} \\
\text { value }\end{array}$} & \multirow{2}{*}{$\begin{array}{l}\mathrm{q} \\
\text { value }\end{array}$} \\
\hline & & & $\mathrm{AA}$ & $\mathrm{AB}$ & $\mathrm{BB}$ & AA & $\mathrm{AB}$ & $\mathrm{BB}$ & & & \\
\hline $\mathrm{F} 2^{\mathrm{a}-\mathrm{c}}$ & G20210A & rs1799963 & 859 (99) & $13(1)$ & 0 & $304(97)$ & $8(3)$ & 0 & $0.58(0.24-1.4)$ & 0.22 & 0.81 \\
\hline $\mathrm{F} 3^{\mathrm{c}}$ & $A(-603) G$ & rs1361600 & $254(29)$ & $437(49)$ & $193(22)$ & $89(29)$ & $151(49)$ & $70(23)$ & $1.0(0.75-1.3)$ & 0.99 & 0.99 \\
\hline $\mathrm{F} 5^{\mathrm{a}-\mathrm{c}}$ & Arg506Gln & rs6025 & $822(95)$ & $45(5)$ & 0 & $281(96)$ & $13(4)$ & 0 & $1.2(0.63-2.2)$ & 0.60 & 0.81 \\
\hline $\mathrm{F} 13 \mathrm{~A} 1^{\mathrm{a}-\mathrm{c}}$ & Val34Leu & rs5985 & $457(54)$ & $344(41)$ & $49(6)$ & $171(58)$ & $103(35)$ & $23(8)$ & $1.2(0.89-1.5)$ & 0.26 & 0.81 \\
\hline $\mathrm{F} 13 \mathrm{~A} 1^{\mathrm{c}}$ & Tyr204Phe & rs3024477 & $827(94)$ & $53(6)$ & $1(0)$ & $298(96)$ & $12(4)$ & 0 & $1.6(0.86-3.1)$ & 0.14 & 0.81 \\
\hline $\mathrm{F} 13 \mathrm{~A} 1^{\mathrm{c}}$ & Pro564Leu & rs5982 & $573(65)$ & $266(30)$ & $44(5)$ & $196(64)$ & $103(34)$ & $8(3)$ & $0.96(0.73-1.3)$ & 0.74 & 0.85 \\
\hline $\mathrm{F} 13 \mathrm{~B}^{\mathrm{c}}$ & His95Arg & rs6003 & $715(81)$ & $163(19)$ & $5(1)$ & $266(87)$ & $37(12)$ & $4(1)$ & $1.5(1.1-2.2)$ & 0.03 & 0.29 \\
\hline $\mathrm{FGA}^{\mathrm{c}}$ & Thr312Ala & rs6050 & $450(51)$ & $358(41)$ & $70(8)$ & $160(54)$ & $111(37)$ & $28(9)$ & $1.1(0.84-1.4)$ & 0.50 & 0.81 \\
\hline $\mathrm{FGB}^{\mathrm{c}}$ & $\mathrm{G}(-854) \mathrm{A}$ & rs1800791 & $642(73)$ & $225(26)$ & $16(2)$ & $225(73)$ & $77(25)$ & $8(3)$ & $1.0(0.74-1.3)$ & 0.97 & 0.99 \\
\hline $\mathrm{FGB}^{\mathrm{a}-\mathrm{c}}$ & $G(-455) A$ & rs1800790 & $526(61)$ & $315(36)$ & $27(3)$ & $197(65)$ & $92(30)$ & $14(5)$ & $1.2(0.92-1.6)$ & 0.17 & 0.81 \\
\hline $\mathrm{FGG}^{\mathrm{c}}$ & G7874A & rs2066861 & $469(53)$ & 345 (39) & $64(7)$ & $168(55)$ & $113(37)$ & $26(9)$ & $1.1(0.81-1.4)$ & 0.69 & 0.84 \\
\hline $\mathrm{FGG}^{\mathrm{b}, \mathrm{c}}$ & T9340C & rs1049636 & $438(50)$ & $365(41)$ & $80(9)$ & $157(51)$ & $118(38)$ & $33(11)$ & $1.1(0.82-1.4)$ & 0.68 & 0.84 \\
\hline FGG & G5836A & rs2066860 & $825(94)$ & $57(7)$ & 0 & $288(93)$ & $22(7)$ & $1(0)$ & $0.87(0.52-1.4)$ & 0.57 & 0.81 \\
\hline PAI- $1^{\mathrm{c}}$ & $4 \mathrm{G} / 5 \mathrm{G}^{\mathrm{c}}$ & rs1799889 & $165(20)$ & $415(49)$ & $261(31)$ & $82(27)$ & $157(51)$ & $71(23)$ & $1.5(1.1-2.0)$ & 0.01 & 0.29 \\
\hline $\mathrm{TPA}^{\mathrm{a}-\mathrm{c}}$ & $\mathrm{C} 7351 \mathrm{~T}$ & rs2020918 & $376(43)$ & $415(47)$ & $86(10)$ & $132(43)$ & $147(47)$ & $31(10)$ & $0.99(0.76-1.3)$ & 0.93 & 0.99 \\
\hline VKORC-1 $1^{\mathrm{a}, \mathrm{c}}$ & $\mathrm{T} 2255 \mathrm{C}$ & rs2359612 & $370(42)$ & $374(42)$ & $136(16)$ & $116(38)$ & $148(48)$ & $44(14)$ & $0.83(0.64-1.1)$ & 0.18 & 0.81 \\
\hline $\mathrm{VWF}^{\mathrm{a}, \mathrm{c}}$ & Thr789Ala & rs1063856 & $397(45)$ & $390(45)$ & $88(10)$ & $134(43)$ & $138(44)$ & $39(13)$ & $0.91(0.70-1.2)$ & 0.49 & 0.81 \\
\hline $\mathrm{GP}_{1 B A}{ }^{\mathrm{a}, \mathrm{c}}$ & $\mathrm{T}(-5) \mathrm{C}$ & rs2243093 & $663(76)$ & $195(22)$ & $18(2)$ & $239(79)$ & 49 (16) & $16(5)$ & $1.2(0.86-1.6)$ & 0.30 & 0.81 \\
\hline $\mathrm{GP}_{1 B A} \mathrm{a}^{\mathrm{a}-\mathrm{c}}$ & Thr145Met & rs6065 & $749(85)$ & $130(15)$ & $4(1)$ & $259(83)$ & $51(16)$ & $2(1)$ & $0.87(0.62-1.2)$ & 0.45 & 0.81 \\
\hline GP6 $^{\mathrm{b}}$ & Ser219Pro & rs1613662 & $610(69)$ & $247(28)$ & $22(3)$ & $222(71)$ & $77(25)$ & $13(4)$ & $1.1(0.82-1.4)$ & 0.56 & 0.81 \\
\hline $\mathrm{GP}^{\mathrm{b}}$ & Thr249Ala & rs2304167 & $590(67)$ & $262(30)$ & $32(4)$ & $215(70)$ & $83(27)$ & $11(4)$ & $1.1(0.86-1.5)$ & 0.36 & 0.81 \\
\hline GP6 & Gln317Leu & rs1654413 & $587(67)$ & 257 (29) & $31(4)$ & $216(70)$ & $82(27)$ & $11(4)$ & $1.1(0.86-1.5)$ & 0.36 & 0.81 \\
\hline GP6 & His322Asn & rs1671152 & $624(71)$ & $237(27)$ & $22(3)$ & $226(72)$ & $74(24)$ & $12(4)$ & $1.1(0.82-1.5)$ & 0.55 & 0.81 \\
\hline
\end{tabular}

Gene symbols: F2 = coagulation factor II; F3 = tissue factor; F5 = coagulation factor V; F13A1 = coagulation factor XIII subunit A; F13B = coagulation factor XIII subunit $\mathrm{B}$; FGA = fibrinogen alpha; FGB = fibrinogen beta; FGG = fibrinogen gamma; PAI-1 = plasminogen activator inhibitor-1; $\mathrm{TPA}=$ tissue plasminogen activator; VKORC-1 = vitamin K epoxide reductase complex-1; VWF = von Willebrand factor; GP1BA = glycoprotein 1balpha; GP6 = glycoprotein VI. The total number of genotypes for each gene

variant does not add up to the total number of subjects because genotype was undetermined in some subjects. AA = Wild-type homozygotes; $\mathrm{AB}=$ variant heterozygotes; $\mathrm{BB}=$ variant homozygotes. For PAI-1 4G/5G: $\mathrm{AA}=5 \mathrm{G} / 5 \mathrm{G} ; \mathrm{AB}=5 \mathrm{G} / 4 \mathrm{G} ; \mathrm{BB}=4 \mathrm{G} / 4 \mathrm{G}$.

a Associated with ischemic stroke in at least one previous study. b Associated with myocardial infarction in at least one previous study. ${ }^{c}$ Evidence of functionality (effect on protein level or protein function).

Despite the sample size and achievement of predefined power requirements [5], we cannot exclude falsenegative findings. Meta-analyses of genetic association studies report odds ratios below 1.5 for most variants [3, 4]. The range of odds ratios in our study is in line with these moderate estimates. One other aspect may contribute to the lack of association we found. Genetic differences between patients surviving or dying after CIAO may be less pronounced than genetic differences between patients with CIAO and healthy subjects. This hypothesis is supported by the finding that family history of stroke is associated with stroke in healthy subjects [1] but not with subsequent stroke in patients with a history of TIA [15].

We were able to study a homogeneous Dutch population that consisted mainly of Caucasian stroke patients of European descent. We cannot exclude some admixture of participants of non-European descent. However, a metaanalysis showed genetic associations with ischemic stroke to be similar among study populations of Asian and Eu- ropean descent, suggesting differential genetic effects by ethnicity may be limited [16].

Strengths of our study are the sample size, the availability of long-term follow-up (16.8 years) after stroke, the well defined phenotype [17] and the use of a suitable statistical method to account for multiple testing [18].

In conclusion, in this hospital-based study mortality after CIAO was associated with none of 23 prothrombotic gene variants. Prothrombotic gene variants do not appear to play an important role in mortality after cerebral ischemia.

\section{Acknowledgments}

This study was supported by a grant from the Medical and Health Research Programme of the Netherlands Organisation for Scientific Research (NWO), grant No. 904-61-190. The authors thank J. van der Meijden, P.J. Noordijk, R.H.A.M. Vossen and S. Greve for performing the genotyping assays. Members of the SMART study group are listed in Simons et al. [6]. 


\section{References}

1 Flossmann E, Schulz UG, Rothwell PM: Systematic review of methods and results of studies of the genetic epidemiology of ischemic stroke. Stroke 2004;35:212-227.

$\checkmark 2$ Jerrard-Dunne P, Cloud G, Hassan A, Markus HS: Evaluating the genetic component of ischemic stroke subtypes: a family history study. Stroke 2003;34:1364-1369.

$\checkmark 3$ Casas JP, Hingorani AD, Bautista LE, Sharma P: Meta-analysis of genetic studies in ischemic stroke: thirty-two genes involving approximately 18,000 cases and 58,000 controls. Arch Neurol 2004;61:1652-1661.

$\checkmark 4$ Ye Z, Liu EH, Higgins JP, Keavney BD, Lowe GD, Collins R, Danesh J: Seven haemostatic gene polymorphisms in coronary disease: meta-analysis of 66,155 cases and 91,307 controls. Lancet 2006;367:651-658.

$\checkmark 5$ Pruissen DM, Kappelle LJ, Algra A: Polymorphisms and Risk of Ischemic Stroke (POLARIS) study: rationale and design. Eur Neurol 2004;51:30-34.

-6 Simons PC, Algra A, van de Laak MF, Grobbee DE, van der Graaf Y: Second manifestations of ARTerial disease (SMART) study: rationale and design. Eur J Epidemiol 1999; 15:773-781.
7 ESPRIT Study Group: Aspirin plus dipyridamole versus aspirin alone after cerebral ischemia of arterial origin (ESPRIT): randomised controlled trial. Lancet 2006;367: 1665-1673.

-8 van Wijk I, Kappelle LJ, van Gijn J, Koudstaal PJ, Franke CL, Vermeulen M, Gorter JW, Algra A: Long-term survival and vascular event risk after transient ischaemic attack or minor ischaemic stroke: a cohort study. Lancet 2005;365:2098-2104.

9 Livak KJ: Allelic discrimination using fluorogenic probes and the $5^{\prime}$ nuclease assay. Genet Anal 1999;14:143-149.

10 Erali M, Pounder JI, Woods GL, Petti CA, Wittwer CT: Multiplex single-color PCR with amplicon melting analysis for identification of Aspergillus species. Clin Chem 2006;52:1443-1445.

11 Benjamini Y, Hochberg Y: Controlling the false discovery rate: a practical and powerful approach to multiple testing. J R Statist Soc B 1995;57:289-300.

12 Smith NL, Hindorff LA, Heckbert SR, Lemaitre RN, Marciante KD, Rice K, Lumley T, Bis JC, Wiggins KL, Rosendaal FR, Psaty BM: Association of genetic variations with nonfatal venous thrombosis in postmenopausal women. JAMA 2007;297:489-498.
13 Pruissen DM, Rosendaal FR, Frijns CJ, Kappelle LJ, Vos HL, Algra A: Prothrombotic gene variation and new vascular events after cerebral ischemia of arterial origin. JThromb Haemost 2008;6:1639-1644.

14 Colhoun HM, McKeigue PM, Davey Smith G: Problems of reporting genetic associations with complex outcomes. Lancet 2003; 361:865-872.

15 Flossmann E, Rothwell PM: Family history of stroke does not predict risk of stroke after transient ischemic attack. Stroke 2006;37: 544-546.

16 Ariyaratnam R, Casas JP, Whittaker J, Smeeth L, Hingorani AD, Sharma P: Genetics of ischaemic stroke among persons of non-European descent: a meta-analysis of eight genes involving approximately 32,500 individuals. PLoS Med 2007;4:e131.

17 Dichgans M, Markus HS: Genetic association studies in stroke: methodological issues and proposed standard criteria. Stroke 2005; 36:2027-2031.

18 Dupuis J, O’Donnell CJ: Interpreting results of large-scale genetic association studies: separating gold from fool's gold. JAMA 2007; 297:529-531. 